\title{
EVALUATION OF A CASE STUDY TO DESIGN A BIM-BASED CYCLE PLANNING CONCEPT
}

\author{
Paul Häringer ${ }^{1}$ and André Borrmann ${ }^{2}$
}

\begin{abstract}
Cycle Planning, or Takt Time Planning, is a key method to reduce the variability between different activities within the execution of a construction. A construction section such as a floor consists of multiple work zones, which should have continuous flow and similar cycle times to efficiently coordinate needed resources. However, for concrete structures it is often difficult to find suitable sizes of casting segments and their grouping to work zones. Nowadays, scheduling experts usually use their practical experience to find an intuitive solution for Cycle Planning, which might be sub-optimal. The objective of our research is thus to develop a semiautomatic method to generate optimal work zones for a cycle. The proposed solution is a BIM-based Cycle Planning concept for the cast in-situ construction method of walls. This paper lays the foundation for our concept and evaluates different designs of Cycle Planning layouts to ensure the practical relevance of the generated work zones. We provide an approach to the semiautomatic method: after splitting all wall objects into smaller sections, an optimization algorithm aggregates wall sections into casting segments and casting segments into work zones.
\end{abstract}

\section{KEYWORDS}

BIM, Cycle Planning, Takt Time Planning, Simulation, Local Breakdown Structure.

\section{INTRODUCTION}

Cycle Planning (CP) is a method to efficiently construct concrete structures cast in-situ. The preferred way to achieve a continuous flow is to schedule multiple casting segments and cycles throughout the floor of a building. The number and size of casting segments have a significant impact on the success of CP (Kenley and Seppänen 2010). CP is often unique to each building and time-consuming. The result is heavily dependent on the available practical experience. Building Information Modeling (BIM) is suitable for getting accurate quantity take-offs and makes it possible to speed up the planning process (Borrmann et al. 2015; MacLeamy 2004). Therefore, BIM helps to include the

\footnotetext{
1 Research Associate, Dept. for Civil, Geo and Environmental Engineering, Technical University of Munich, Germany, +49 89 289-23294, paul.haeringer@tum.de

2 Professor, Chair of Computational Modeling and Simulation, Dept. for Civil, Geo and Environmental Engineering, Technical University of Munich, Germany, +49 89 289-23047, andre.borrmann@ tum.de
} 
construction process further into the design phase so that $\mathrm{CP}$ could start already during the design process. BIM provides a very useful digital basis for creating the required breakdown structures like splitting wall objects into smaller wall sections and using their individual attributes. The next step after the generation of casting segments and their aggregation into suitable work zones is the optimal selection of formwork. In a Building Information Model, casting segments are available as objects or as an aggregation of multiple objects. Such objects and BIM processes in general can be used for automating formwork layouts (Singh et al. 2017). Maximum reuse of formwork in consecutive work zones reduces the amount of waste. Such work zones should be of similar size, shape, and work amount (American Concrete Institute Committee 347 2014). There are methods to optimize formwork in terms of reuse and minimum rental cost between already existing work zones, e.g. (Biruk and Jaskowski 2017). The research represented in this paper lays the foundation for filling the gap between the use of a general Building Information Model and automatic design of formwork layouts.

In the first part of this paper, we describe different layouts of CP. We show how three experts from three different companies, hereinafter called designers, designed a layout of $\mathrm{CP}$ for the same project and construction section with identical boundary conditions. Two of them work for formwork companies and one was the foreman responsible for the real construction project. According to the evaluation of these different layouts, we want to illustrate our approach - a BIM-Based Cycle Planning concept. The objective is to develop a semiautomatic method to generate optimal work zones for a cycle. We implemented a software prototype to prove the validity of the main elements of the developed concept. However, this paper does not validate the whole concept as we are still working on developing the concept further.

\section{CASE STUDY OF CYCLE PLANNING}

The initial step to reach our objective is to understand the Cycle Planning method. In order to understand it, we use a case study, which provides information about the process steps and individual rule interpretations. This is helpful for finding hard and soft constraints to generate a layout of CP more automatically.

\subsection{Description and Structure of The CaSe Study}

The selected case study is a construction section of a residential building. The building covers a surface area of about $750 \mathrm{~m}^{2}$ over five levels and it is one of a group of buildings. Each level consists of eight apartments, two staircases, and an elevator shaft. The material of the shell construction is reinforced concrete. The construction company created the wall on site with the cast in-situ construction method. Based on the original plans, we created a Building Information Model. The designers were provided with the model and time schedule. The operating construction company used panel formwork as it is practicable for this type of building with a simple and linear geometry (Hoffmann et al. 2012).

In summary, these are the components and boundary conditions provided to the designers:

- The Building Information Model with geometrical and material information. 
- The time schedule of 10 working days / 14 days with weekends with the time duration (time limit) for the construction section.

- The limitation to use only panel formwork and one tower crane.

We received different results of each of designers (Figure 1).
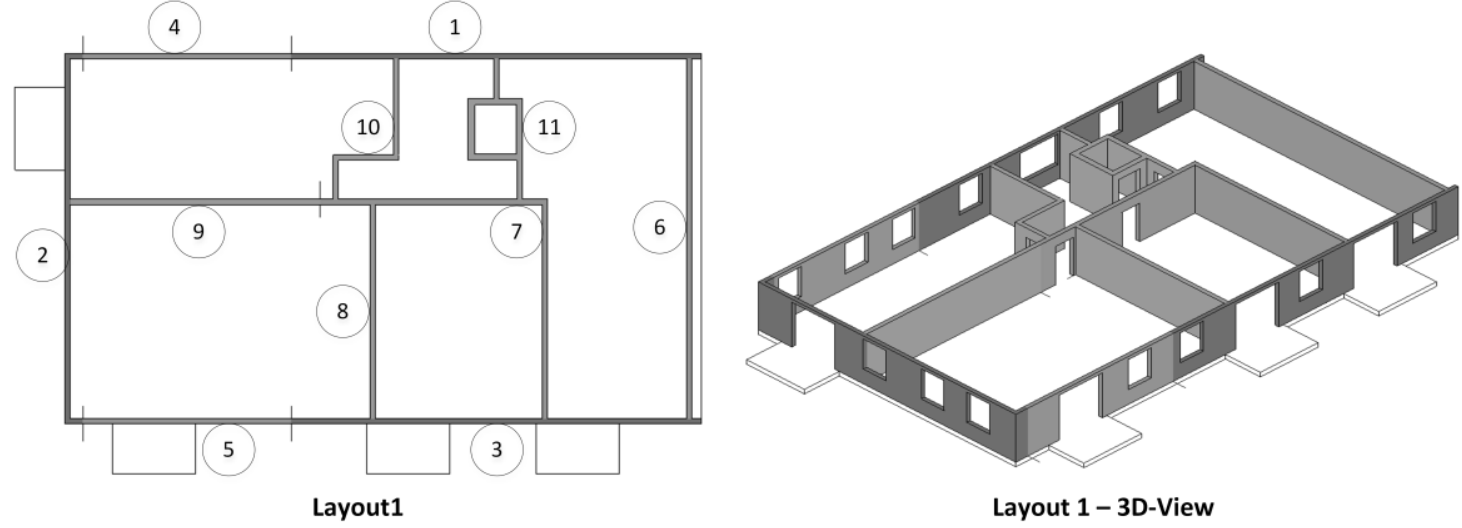

Layout 1 - 3D-View
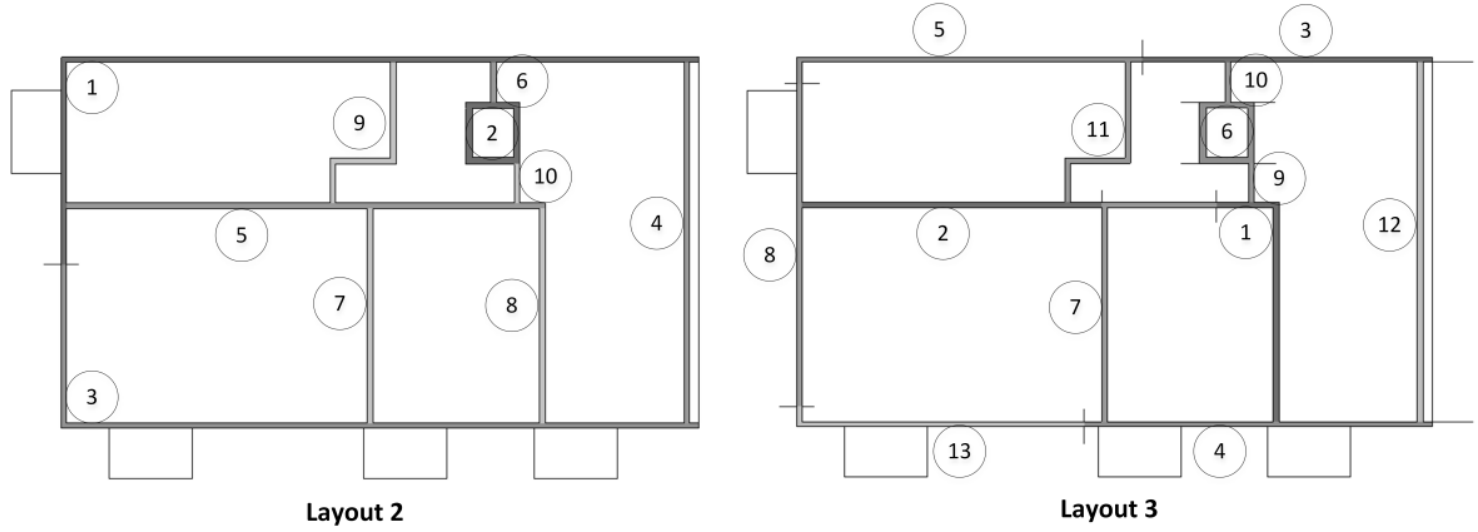

Figure 1: Visualization of the different layouts provided by the designers related to their work zones and associated casting segments numbered 1 to 11 (Layout 1), 1 to 10 (Layout 2) and 1 to 13 (Layout 3).

Each number represents a casting segment. A group of identically colored casting segments forms a work zone. Therefore, a work zone represents all the elements that are going to be built at the same time on site. At least two joints separate a casting segment. Because the design of the provided Building Information Model did not consider casting segments, we had to split already modeled walls manually for each received layout.

We received different data formats for the layouts from the designers. One designer used a 2D-printout of the construction section and different colored pencils. The other two designers used digital tools. One of them used the software Revit and DokaCAD, while the other used solely PeriCAD.

\subsection{Data Evaluation}

Before analyzing the layouts and their relation to the predetermined time schedule, we have to consider the technical characteristics and constraints. This is the initial step to 
find hard and soft constraints to generate a layout of CP more automatically. Table 1 lists the quantities of the properties Length $[\mathrm{m}]$, Volume $\left[\mathrm{m}^{3}\right]$ and Gross Side Area $\left[\mathrm{m}^{2}\right]$ for each casting segment.

Table 1: Comparison of the different layouts from Figure 1 related to their grouping into work zones (color) and properties of each casting segment (number). W stands for window and D stands for door opening.

\begin{tabular}{|c|c|c|c|c|c|c|c|c|c|c|c|c|c|c|c|}
\hline \multirow{3}{*}{ 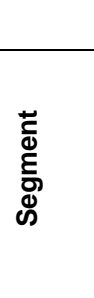 } & \multicolumn{5}{|c|}{ Layout1 } & \multicolumn{5}{|c|}{ Layout 2} & \multicolumn{5}{|c|}{ Layout 3} \\
\hline & 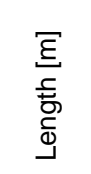 & 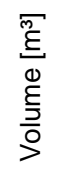 & 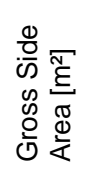 & & $\begin{array}{l}\frac{n}{2} \\
\frac{1}{2} \\
\frac{1}{2}\end{array}$ & 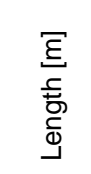 & 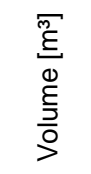 & 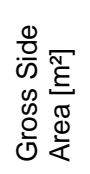 & & 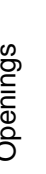 & 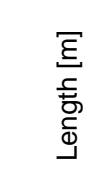 & 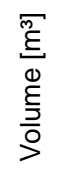 & 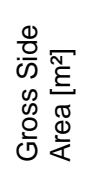 & & 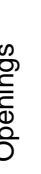 \\
\hline & & & & W & $D$ & & & & W & $\mathrm{D}$ & & & & W & $\mathrm{D}$ \\
\hline 1 & 16.35 & 6.67 & 43.66 & 4 & 0 & 33.42 & 12.79 & 89.27 & 8 & 1 & 11.03 & 6.48 & 29.44 & 0 & 0 \\
\hline 2 & 15.76 & 5.85 & 42.26 & 3 & 1 & 8.24 & 4.92 & 22.00 & 0 & 1 & 11.96 & 6.55 & 31.93 & 0 & 1 \\
\hline 3 & 16.35 & 4.94 & 43.65 & 3 & 2 & 31.66 & 10.56 & 84.53 & 6 & 3 & 11.58 & 4.56 & 30.91 & 3 & 0 \\
\hline 4 & 8.31 & 3.12 & 22.19 & 3 & 0 & 14.36 & 8.44 & 38.34 & 0 & 0 & 13.90 & 4.07 & 37.12 & 2 & 2 \\
\hline 5 & 8.31 & 2.76 & 22.19 & 1 & 1 & 19.04 & 10.23 & 50.82 & 0 & 2 & 14.64 & 6.06 & 39.10 & 4 & 0 \\
\hline 6 & 14.36 & 8.44 & 38.34 & 0 & 0 & 1.60 & 0.94 & 4.26 & 0 & 0 & 8.24 & 4.92 & 22.00 & 0 & 1 \\
\hline 7 & 17.60 & 9.86 & 49.15 & 0 & 2 & 8.55 & 5.02 & 22.82 & 0 & 0 & 13.14 & 7.24 & 35.08 & 0 & 1 \\
\hline 8 & 8.55 & 5.02 & 22.82 & 0 & 0 & 8.55 & 5.02 & 22.82 & 0 & 0 & 12.90 & 4.26 & 34.26 & 3 & 1 \\
\hline 9 & 9.98 & 5.86 & 26.65 & 0 & 0 & 8.01 & 4.23 & 21.38 & 0 & 1 & 1.55 & 0.44 & 4.14 & 0 & 1 \\
\hline 10 & 8.01 & 4.24 & 21.38 & 0 & 1 & 1.55 & 0.44 & 4.14 & 0 & 1 & 1.60 & 0.94 & 4.26 & 0 & 0 \\
\hline 11 & 11.39 & 6.31 & 27.95 & 0 & 2 & & & & & & 8.01 & 4.23 & 21.37 & 0 & 1 \\
\hline 12 & & & & & & & & & & & 14.36 & 8.44 & 38.34 & 0 & 0 \\
\hline 13 & & & & & & & & & & & 12.06 & 4.32 & 32.19 & 2 & 1 \\
\hline Total: & 135 & 63 & 360 & 14 & 9 & 135 & 63 & 360 & 14 & 9 & 135 & 63 & 360 & 14 & 9 \\
\hline
\end{tabular}

Every row in Table 1 represents a casting segment. The numbers of the casting segments refer to the numbers shown in Figure 1. The casting segments with the same color within a layout belong to the same work zone. A vertical line separates the work zones. Additionally, Table 1 contains the number of openings for windows (W) and doors (D) for each casting segment. This quantity is crucial because every opening influences the possible size of casting segments. On the one hand, more openings lead to increased time for setting and stripping the formwork, because of box-outs on sheathings. On the other hand, the casting volume is decreased and thus the time needed for reinforcing and pouring is shorter because fewer rebar elements are required.

None of the layouts had joints at openings. The reason is that joints through openings behave like a cantilever. It is like a beam, which is anchored at one end to a support. A structural engineer usually does not consider this for walls during the structural analysis. If there is a cantilever during the execution process on site, then the engineers must 
consider this, because it changes the internal forces (Fingerloos, Hegger and Zilch, 2012). This is an additional challenge during the design process. Therefore, the rule of not placing joints at openings is considered as a hard constraint.

By contrast, the following rules are soft constraints. One method to avoid cracks due to shrinking is to provide adequate construction joints (Woodson, 2012). With respect to limiting the length of casting segments, a rule from one designer is to limit the length to around 12 meters, which is shown on Layout 3 in Table 1. The maximum length in Layout 3 has casting segment 5 with $14.64 \mathrm{~m}$. Such a length limitation is also observable in the layout pattern for Cycle Planning (Institut für Zeitwirtschaft und Betriebsberatung Bau, 2013). In corners and especially at building edges, walls often need additional reinforcement stirrups (Fingerloos et al. 2012). Joints in corners increase the time and the effort of rebar bracing with stirrups. Another disadvantage of joints in corners, especially in the corner of a building, is the reduced space for the bulkhead formwork. The designer's idea is to overlap such corners through a length expansion of a casting segment. The application of this rule can be seen for casting segments 1 (Layout 1), 2 and 3 (Layout 2) and 8 (Layout 3) in Figure 1. A suitable solution for rebar bracing in T-type corners is the use of rebar connection systems.

The essential rules we can derive from the layouts are:

- No joints through openings.

- Limit the length of casting segments.

- Avoid joints in corners, especially in L-type corners in building corners.

\subsection{Different Layouts RELATING TO TAKT TIME}

According to Frandson (Frandson et al. July 2013) "Takt-time is the unit of time within which a product must be produced (supply rate) in order to match the rate at which that product is needed (demand rate) ". In our case, the product is a finished work zone (a piece of wall) and we need all products finished within 14 days. As mentioned, we have 10 working days and with an assumption of 8.5 working hours per day, we get a total working time of 85 working hours. For Layout 1 with three working zones, we get a takt time of 28.33 hours/product. Both Layouts 2 and 3 have four working zones, so for them, we get a takt time of 21.25 hours/product.

In order to calculate the time for each activity, we used the denoted quantities from the Building Information Model (Table 1) and multiplied them by performance factors. We estimated the amount of rebar using a percentage of the casting volume and calculated the needed time for the reinforcement activity (Hofstadler 2007). Since formwork elements are used over and over in different work zones, box-outs on sheathings will change their position over time. We took this into account by considering such changes as well as openings with constant time durations taken from (Institut für Zeitwirtschaft und Betriebsberatung Bau 2013).

Often the construction companies have their own values for the performance factors with an approximate target number of workers they need to meet the activity time. Because we did not get all the detailed data from every designer, we decided to use 
values that were close to the designer's data as well as to the data denoted in guidelines (Institut für Zeitwirtschaft und Betriebsberatung Bau 2013).

Table 2 illustrates our calculated duration times for the activities setting, reinforcing, concreting and stripping, respectively.

Table 2: Calculated duration times of each activity and cycle time (Sum Work Zone) for the work zones as well as their mean absolute derivation related to the takt time.

\begin{tabular}{|c|c|c|c|c|c|c|c|c|c|c|c|}
\hline \multirow[b]{2}{*}{ Activity } & \multicolumn{3}{|c|}{ Layout 1} & \multicolumn{4}{|c|}{ Layout 2} & \multicolumn{4}{|c|}{ Layout 3} \\
\hline & $\begin{array}{l}\overline{0} \\
\stackrel{0}{0} \\
\text { N } \\
\text { x } \\
\grave{3}\end{array}$ & 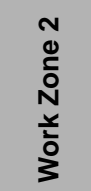 & 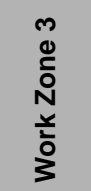 & $\begin{array}{l}\bar{\Phi} \\
\stackrel{0}{0} \\
\text { N } \\
\text { 늠 } \\
\grave{3}\end{array}$ & 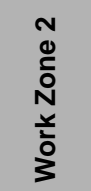 & 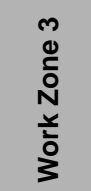 & 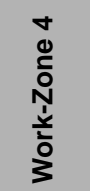 & 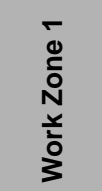 & 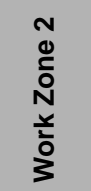 & 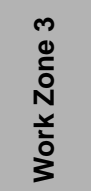 & 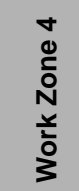 \\
\hline Setting & 9.81 & 9.09 & 6.67 & 8.34 & 6.53 & 6.01 & 4.67 & 6.17 & 7.36 & 7.18 & 4.72 \\
\hline Reinforcing & 9.25 & 12.82 & 11.36 & 9.39 & 5.60 & 10.39 & 7.79 & 9.32 & 7.98 & 9.06 & 6.76 \\
\hline Concreting & 5.92 & 5.13 & 3.70 & 5.00 & 4.00 & 3.20 & 2.53 & 3.40 & 4.41 & 4.20 & 2.60 \\
\hline Stripping & 2.62 & 3.63 & 3.21 & 2.66 & 1.58 & 2.94 & 2.21 & 2.64 & 2.26 & 2.57 & 1.91 \\
\hline Sum Work Zone: & 27.61 & 30.66 & 24.95 & 25.38 & 17.71 & 22.54 & 17.20 & 21.53 & 22.00 & 23.01 & 16.00 \\
\hline Takt time: & \multicolumn{3}{|c|}{28.33} & \multicolumn{4}{|c|}{21.25} & \multicolumn{4}{|c|}{21.25} \\
\hline Derivation: & 0.72 & 2.33 & 3.38 & 4.13 & 3.54 & 1.29 & 4.05 & 0.28 & 0.75 & 1.76 & 5.25 \\
\hline Total Derivation: & \multicolumn{3}{|c|}{6.43} & \multicolumn{4}{|c|}{13.01} & \multicolumn{4}{|c|}{8.04} \\
\hline
\end{tabular}

For the real construction project, our calculations were based on the same trade groupings and number of trade workers. Trade 1 - carpenters, with 4 workers for the activities setting, stripping and concreting. Trade 2 - steel fixer, with 3 workers for the activity reinforcing. If the duration for setting and reinforcing are the same, the waiting time between the two trades is reduced significantly. Because of openings and the additional time for out-boxes, activities setting and reinforcing take about the same amount of time in Work Zone 1 - Layout 1 as well as in Layout 2. One possible way of balancing the setting and reinforcement activities is changing the aggregation of smaller wall objects into suitable sizes of casting segments. This we can do automatically in our concept.

The layout with the minimal mean absolute derivation and therefore the best layout is Layout 1 with 6.43 hours. Layout 3 is second with 8.04 and Layout 2 is third with 13.01 hours. In addition to minimizing derivations between cycle and takt time as well as between different duration times of activities, especially the limitation of the maximum length of casting segments and the reuse of formwork are further crucial criteria.

\section{BIM-BASED CYCLE PLANNING CONCEPT}

According to the analyzed and evaluated case study, we defined constraints to develop a first approach of an algorithm to split objects automatically. The main research question is, is there a way to semi automatically create a Cycle Planning layout, which could be more optimal in terms of continuous flow and cycle time? 
Combining such objects into casting segments and work zones is an optimization problem. Therefore, a metaheuristic optimization algorithm can help to create a more optimal solution (Bianchi et al. 2009). Our first approach is to use simulated annealing in combination with a discrete event simulation.

\subsection{CONCEPT OVERVIEW AND DESCRIPTION}

Based on the case study, we designed a BIM-based Cycle Planning concept (Figure 2).

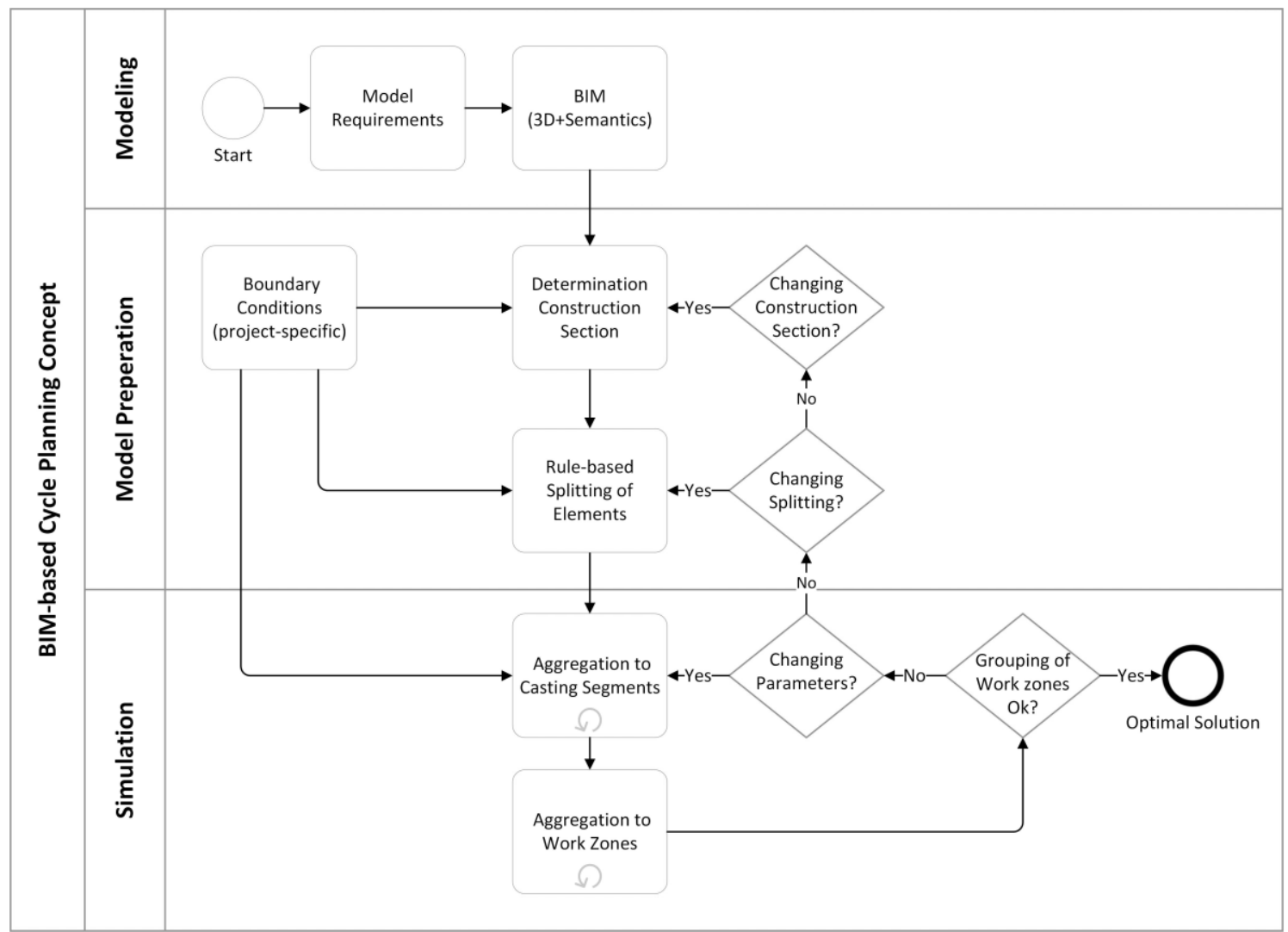

Figure 2: Design of our BIM-based Cycle Planning Concept

The basement in our concept is a Building Information Model. For the project-specific boundary conditions, the next step is to determine suitable construction sections following by a rule-based splitting of objects, which should be semiautomatic. This approach is illustrated in Figure 3 and is based on the binary tree data structure (Garnier and Taylor 2010). 

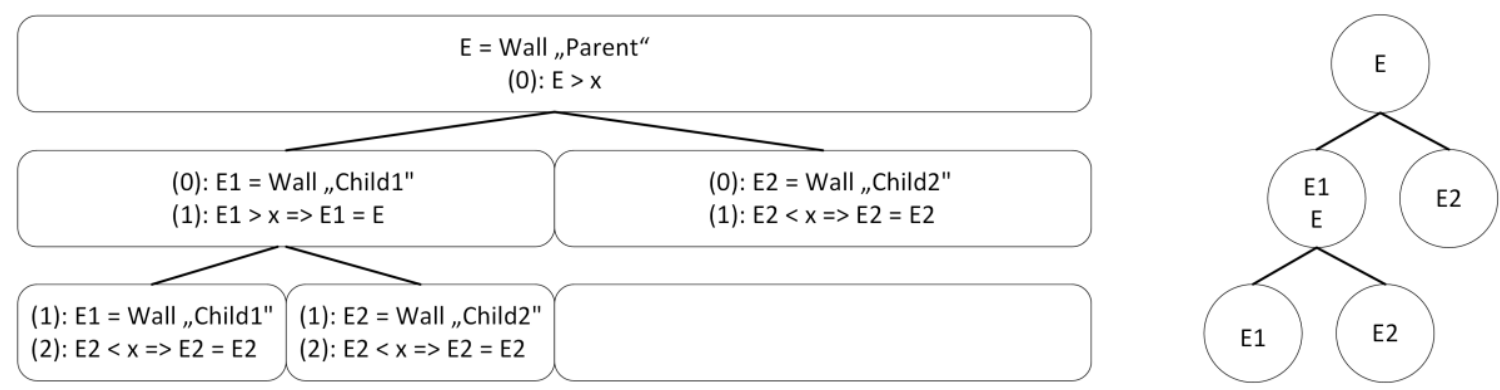

Figure 3: Binary tree approach for a semiautomatic rule-based splitting of objects

An object in a BIM is unique, so splitting one object into multiple objects creates at least two new objects. The root object represents the parent (E) and the two new generated objects are the children (E1 and E2). The variable $\mathrm{x}$ defines, for example, the user input for the maximum length of an object. In the first cycle (0), the algorithm checks whether $\mathrm{E}$ is longer than $\mathrm{x}$. If this term is true, then the children $\mathrm{E} 1$ and $\mathrm{E} 2$ replace E. The second cycle (1) repeats this step with E1 and E2. E2 is shorter than X, so E2 stays $\mathrm{E} 2$. E1 is longer than $\mathrm{x}$, so E1 becomes a root object $\mathrm{E}$. This is repeated until all objects are shorter than $x$, which happens in the next cycle (2).

For the simulation and optimization, we separate the process into two steps. The first step is the aggregation into casting segments and consists of setting one side of the formwork, putting in the required reinforcement, and then setting the formwork on the opposite side. The second step is the aggregation into work zones and consists of concreting and stripping the formwork. For the first step, we implemented a prototype with the software Plant Simulation by Siemens PLM Software. During the implementation, we had support from PPI-Informatik, which is a German company that uses Plant Simulation to simulate and optimize material flow in the process industry.

\subsection{AGGREGATION TO CASTING SEGMENTS}

Our objective function to find an optimal solution for the size of casting segments is a combination of construction time and number of joints. The method we use for the optimization is simulated annealing (Kirkpatrick et al. 1983). With the use of the topological relationships between objects, we know which objects lay side by side and we can aggregate adjoint objects into casting segments.

We prepared a small simulation scenario with six wall objects. The wall objects had different durations for the activities setting and reinforcing. The objective was to find an optimal solution for the size and amount of casting segments. One trade did the setting and the other the reinforcement, so that these activities could be done in parallel. Figure 4 and Figure 5 show different results of two simulation runs with different settings for the objective function. 


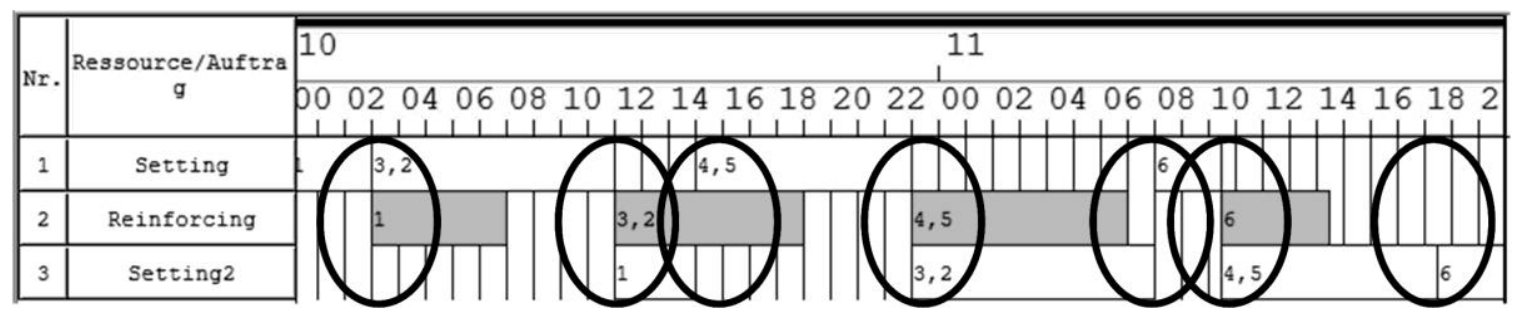

Figure 4: Simulation with a higher objective of minimal construction time

The axis of ordinate shows the activities reinforcing (no. 2) and setting, which is divided into nos. 1 and 3. The axis of abscissae shows the timeline. The bars inside the Gantt chart represent the casting segments. The listed numbers inside show which wall objects belong to the same casting segment.

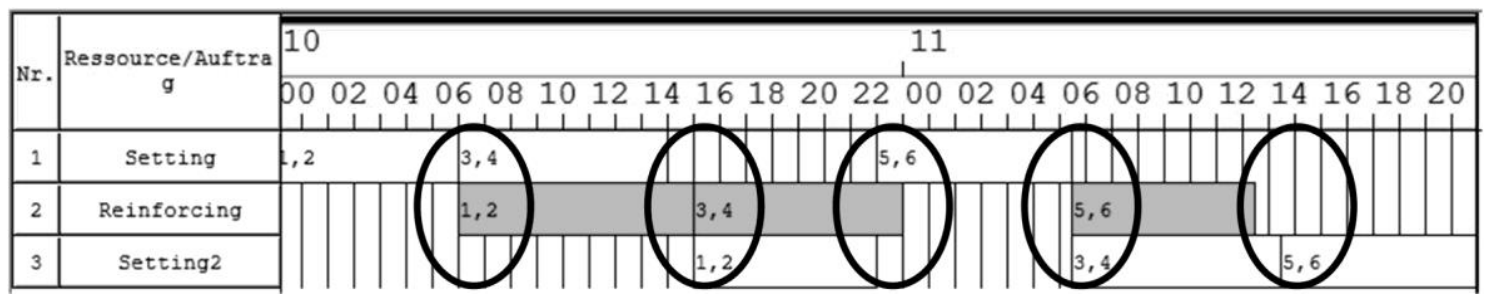

Figure 5: Simulation with a balanced objective between minimal construction time and variability between the activities

The result with a higher objective of minimum construction time aggregates wall object 2 with 3 and 4 with 5 . The result with a balanced objective between minimum construction time and less variability between activities aggregates wall object 1 with 2, 3 with 4 and 5 with 6 . Because of dependencies and waiting times between the activities and trades, the first simulation result is one hour faster than the second. However, the second result has less variability and fewer intersections between the activities, which shows the different number of ovals in Figure 4 and Figure 5. At such intersections, there is a combined effect of dependence and variation. Managing such an intersection is essential to deliver projects in the shortest amount of time (Gregory A. Howell 1999). Reducing the number of intersections means less managing, so it increases the likelihood of delivering a project in a shorter amount of time. Therefore, the second result could be faster than the first.

\section{CONCLUSION AND OUTLOOK}

This paper aims to analyze and evaluate different Cycle Planning layouts of a case study to design a BIM-based Cycle Planning concept. A Building Information Model is the basis for extracting required information easily and consistently. Even for the same wall objects of a construction section, a Cycle Planning layout can look differently. There are many possibilities and it is not easy to find an optimal solution. The results related to the takt time show that work zones have more or less variable cycle times, so there is a need to find better solutions. The represented concept can help to generate Cycle Planning 
layouts more automatically. Our implemented prototype is the first step in generating suitable sizes of casting segments automatically and considering the variability between activities. The simulation results show that a simulation with a balanced objective between minimum construction time and variability between the activities could be more reliable than a simulation with a focus only on minimum construction time.

\section{REFERENCES}

American Concrete Institute Committee 347 (2014). Guide to formwork for concrete: An ACI standard, 347-14, ACI, American Concrete Institute, [Detroit, Michigan].

Bianchi, L., Dorigo, M., Gambardella, L. M., and Gutjahr, W. J. (2009). "A survey on metaheuristics for stochastic combinatorial optimization." Natural Computing, 10.1007/s11047-008-9098-4, 239-287.

Biruk, S., and Jaskowski, P. (2017). "Optimization of Vertical Formwork Layout Plans Using Mixed Integer Linear Programming." Int J Civ Eng, 10.1007/s40999-016-0090-6, 125133.

Borrmann, A., König, M., Koch, C., and Beetz, J. (2015). Building Information Modeling: Technologische Grundlagen und industrielle Praxis, VDI-Buch, Springer Vieweg, Wiesbaden, 10.1007/978-3-658-05606-3.

Fingerloos, F., Hegger, J., and Zilch, K. (2012). Eurocode 2 für Deutschland: DIN EN 19921-1 Bemessung und Konstruktion von Stahlbeton- und Spannbetonbauwerken - Teil 1-1: Allgemeine Bemessungsregeln und Regeln für den Hochbau mit nationalem Anhang ; kommentierte Fassung, Beuth; Ernst \& Sohn, Berlin, Berlin.

Frandson, A., Berghede, K., and Tommelein, I. D. (2013). Takt time planning for construction of exterior cladding, In Proc. 21st Annual Conference of the International Group for Lean Construction.

Garnier, R., and Taylor, J. (2010). Discrete mathematics: Proofs, structures and applications, CRC Press, Boca Raton, Fla.

Gregory A. Howell (1999). WHAT IS LEAN CONSTRUCTION-1999, In Proceedings IGLC. Vol. 7.

Hoffmann, F. H., Motzko, C., and Corsten, B. (2012). Aufwand und Kosten zeitgemäßer Schalverfahren: Kalkulation, Arbeitsvorbereitung, Ausführung, Nachführung, Zeittechnik-Verl., Neu-Isenburg.

Hofstadler, C. (2007). Bauablaufplanung und Logistik im Baubetrieb, Springer-Verlag Berlin Heidelberg, Berlin, Heidelberg.

Institut für Zeitwirtschaft und Betriebsberatung Bau, ed. (2013). Schalarbeiten, Rahmenschalung Wände, Stützenschalung: Richtzeiten ; [Handbuch B3.1/3.2], Zeittechnik-Verl., Neu-Isenburg.

Kenley, R., and Seppänen, O. (2010). Location-based management for construction: Planning, scheduling and control, p. 231, Spon Press, London.

Kirkpatrick, S., Gelatt, C. D., and Vecchi, M. P. (1983). "Optimization by simulated annealing." science, 220(4598), 671-680.

MacLeamy, P. (2004). "MacLeamy curve." Collaboration, Integrated Information, and the Project Lifecycle in Building Design and Construction and Operation (WP-1202).

Singh, M. M., Sawhney, A., and Sharma, V. (2017). "Utilising Building Component Data from BIM for Formwork Planning." AJCEB, 10.5130/AJCEB.v17i4.5546, 20. 